\title{
Low Frequency Raman Spectroscopic Study on Compression-Induced Destabilization in Melt-Quenched Amorphous Celecoxib
}

Kārlis Bērzinş̌sa, Sara J. Fraser-Millera, Thomas Rades ${ }^{\mathrm{b}, \mathrm{c}}$, Keith C. Gordon ${ }^{\mathrm{a}}$

aThe Dodd-Walls Centre for Photonic and Quantum Technologies, Department of Chemistry, University of Otago, Dunedin, New Zealand

${ }^{b}$ Department of Pharmacy, Faculty of Health and Medical Sciences, University of Copenhagen, Copenhagen, Denmark

'Faculty of Science and Engineering, Åbo Akademi University, Turku, Finland

*Corresponding author

\section{Supporting information}

Table S1. Overview of the design of experiments (DOE).

\begin{tabular}{|c|c|c|c|c|}
\hline No. & Cooling-rate, ${ }^{\circ} \mathrm{C} / \mathrm{min}$ & Compression pressure, $\mathrm{MPa}$ & Dwell time, sec & Number of samples \\
\hline 1 & \multirow{5}{*}{$>100^{\circ} \mathrm{C} / \mathrm{min}$ (fast) } & 0 & 0 & 2 \\
\hline 2 & & 125 & 60 & 2 \\
\hline 3 & & 250 & 30 & 3 \\
\hline 4 & & 500 & $0^{*}$ & 2 \\
\hline 5 & & 500 & 60 & 2 \\
\hline 6 & \multirow{5}{*}{$25-30{ }^{\circ} \mathrm{C} / \mathrm{min}$ (slow) } & 0 & 0 & 1 \\
\hline 7 & & 125 & 60 & 1 \\
\hline 8 & & 250 & 30 & 3 \\
\hline 9 & & 500 & $0^{*}$ & 1 \\
\hline 10 & & 500 & 60 & 1 \\
\hline
\end{tabular}

"The dwell time was limited to the minimum.

Table S2. Summary of the independent set of samples, which was analysed only using DSC with a slow heating rate $\left(1^{\circ} \mathrm{C} / \mathrm{min}\right)$.

\begin{tabular}{|c|c|c|c|c|}
\hline No. & Cooling-rate, ${ }^{\circ} \mathrm{C} / \mathrm{min}$ & Compression pressure, $\mathrm{MPa}$ & Dwell time, sec & Number of samples \\
\hline 1 & \multirow{5}{*}{$>100{ }^{\circ} \mathrm{C} / \mathrm{min}$ (fast) } & 0 & 0 & \multirow{5}{*}{3} \\
\hline 2 & & 125 & 60 & \\
\hline 3 & & 250 & 30 & \\
\hline 4 & & 500 & $0^{*}$ & \\
\hline 5 & & 500 & 60 & \\
\hline
\end{tabular}

"The dwell time was limited to the minimum. 
a)

a)

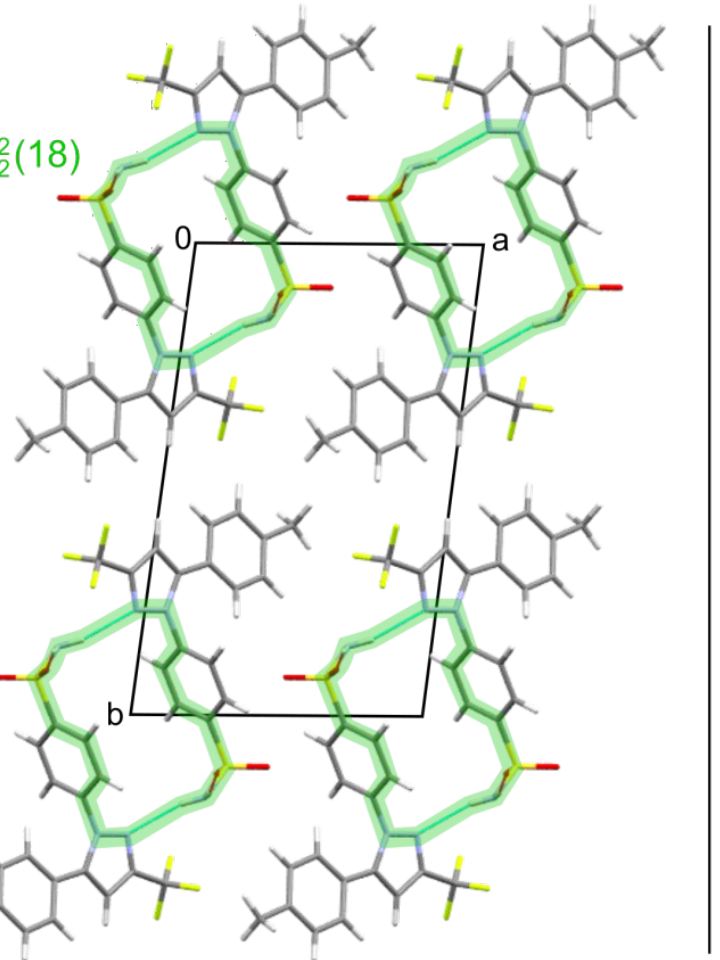

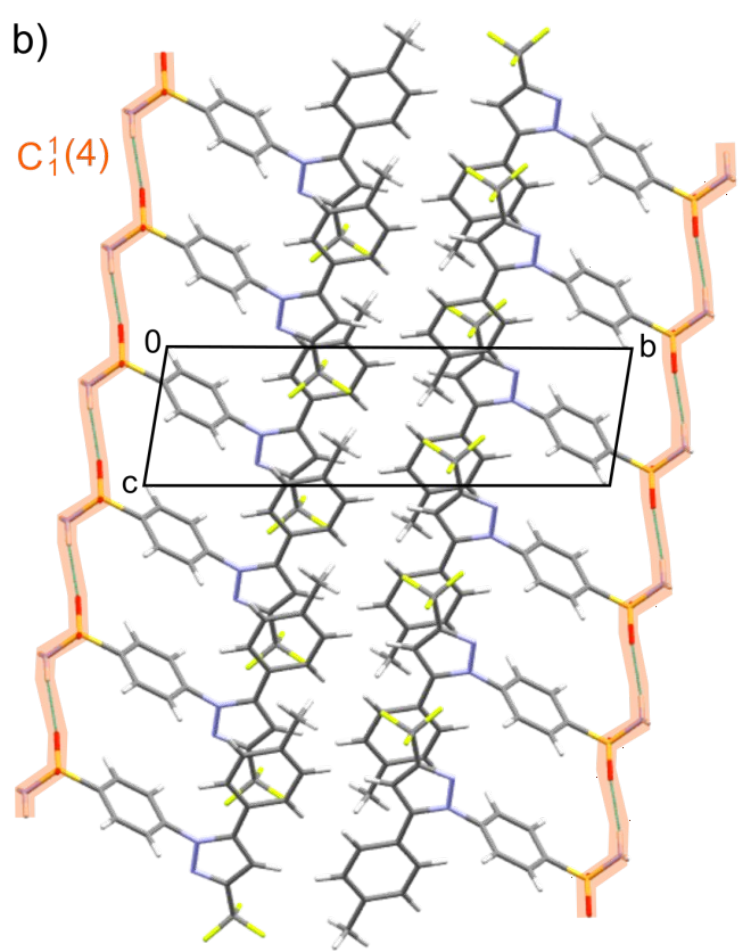

Figure S1. View of the celecoxib form III packing of (a) $R_{2}^{2}(18)$ dimers and (b) $C_{1}^{1}(4)$ chains, which propagate along the $a$-axis in the crystallographic $a b$ plane and $c$-axis in the crystallographic $b c$ plane, respectively.

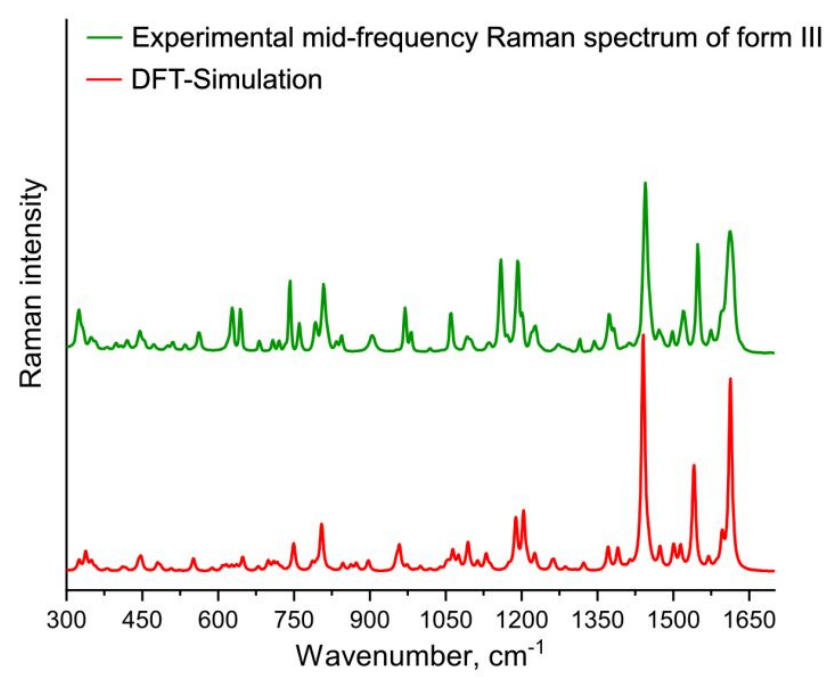

Figure S2. Experimental and DFT-simulated mid-frequency Raman spectra of celecoxib form III. 
Table S3. Vibrational mode assignment for the calculated LFR Raman spectrum of celecoxib form III

\begin{tabular}{|c|c|c|c|c|}
\hline Wavenumber, $\mathrm{cm}^{-1}$ & Symmetry & $\begin{array}{l}\text { Relative } \\
\text { activity }\end{array}$ & Mode type & Principal axis \\
\hline 39.01 & \multirow{23}{*}{$\mathrm{Ag}$} & 278.24 & Torsion & $\mathrm{a}$ \\
\hline 46.25 & & 99.6 & Torsion & $\mathrm{ca}$ \\
\hline 55.02 & & 168.49 & Torsion & ba \\
\hline 60.93 & & 164.68 & Torsion & $\mathrm{ac}$ \\
\hline 66.23 & & 154.98 & Torsion & ba \\
\hline 75.73 & & 260.66 & Torsion & $\mathrm{bc}$ \\
\hline 83.99 & & 166.08 & Torsion & $\mathrm{a}$ \\
\hline 90.14 & & 63.03 & Torsion & bac \\
\hline 94.49 & & 185.49 & $\begin{array}{c}\text { Torsion + Methyl group } \\
\text { rotation }\end{array}$ & $a b c$ \\
\hline 107.43 & & 145.71 & $\begin{array}{c}\text { Torsion + Methyl group } \\
\text { rotation }\end{array}$ & $a b c$ \\
\hline 109.71 & & 143.18 & $\begin{array}{c}\text { Torsion + Methyl group } \\
\text { rotation }\end{array}$ & $a b c$ \\
\hline 122.35 & & 704.19 & Tolyl ring torsion & $\mathrm{ab}$ \\
\hline 135.71 & & 12.44 & Torsion & $\mathrm{ab}$ \\
\hline 137.65 & & 489.86 & Pyrazole ring torsion & $a b$ \\
\hline 149.38 & & 25.92 & Torsion & $a b c$ \\
\hline 162.39 & & 720.94 & Torsion & $\mathrm{ac}$ \\
\hline 176.71 & & 132.73 & Torsion & acb \\
\hline 181.85 & & 179.87 & Torsion & ba \\
\hline 200.66 & & 84.06 & Torsion & ba \\
\hline 208.17 & & 28.72 & Torsion & $\mathrm{abc}$ \\
\hline 227.68 & & 17.97 & $\begin{array}{c}\text { Torsion + Methyl group } \\
\text { stretching }\end{array}$ & $a b c$ \\
\hline 249.10 & & 86.13 & Torsion & $a b c$ \\
\hline 255.42 & & 28.49 & Torsion & ba \\
\hline
\end{tabular}




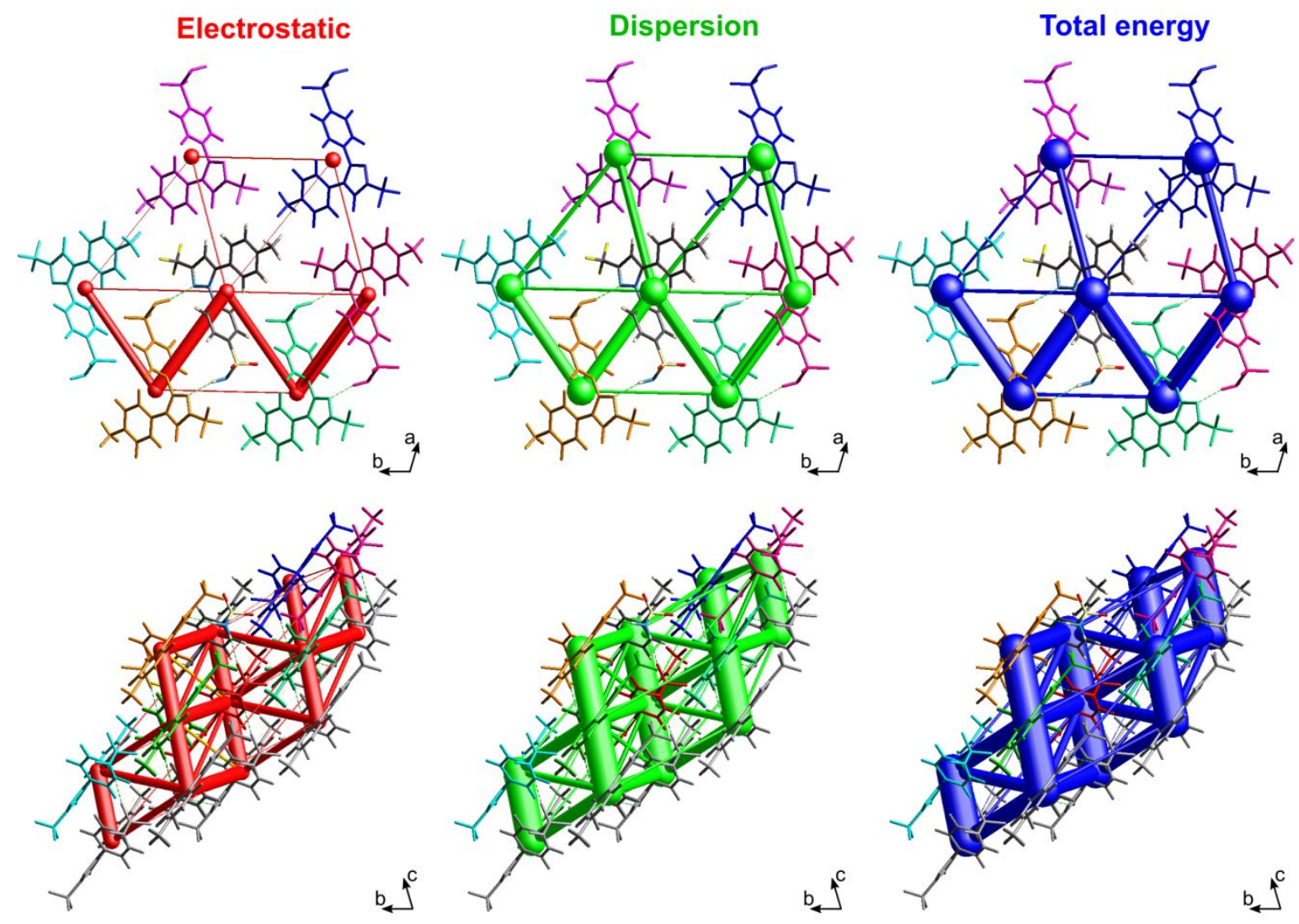

Figure S3. Energy framework diagrams for a cluster of nearest-neighbor molecules in celecoxib form III. All diagrams use the same cylinder scale of 150 for energies.

a) I-Control III-250MPa 60s V-500MPa 60s II - 125MPa 60s IV - 500MPa 0s
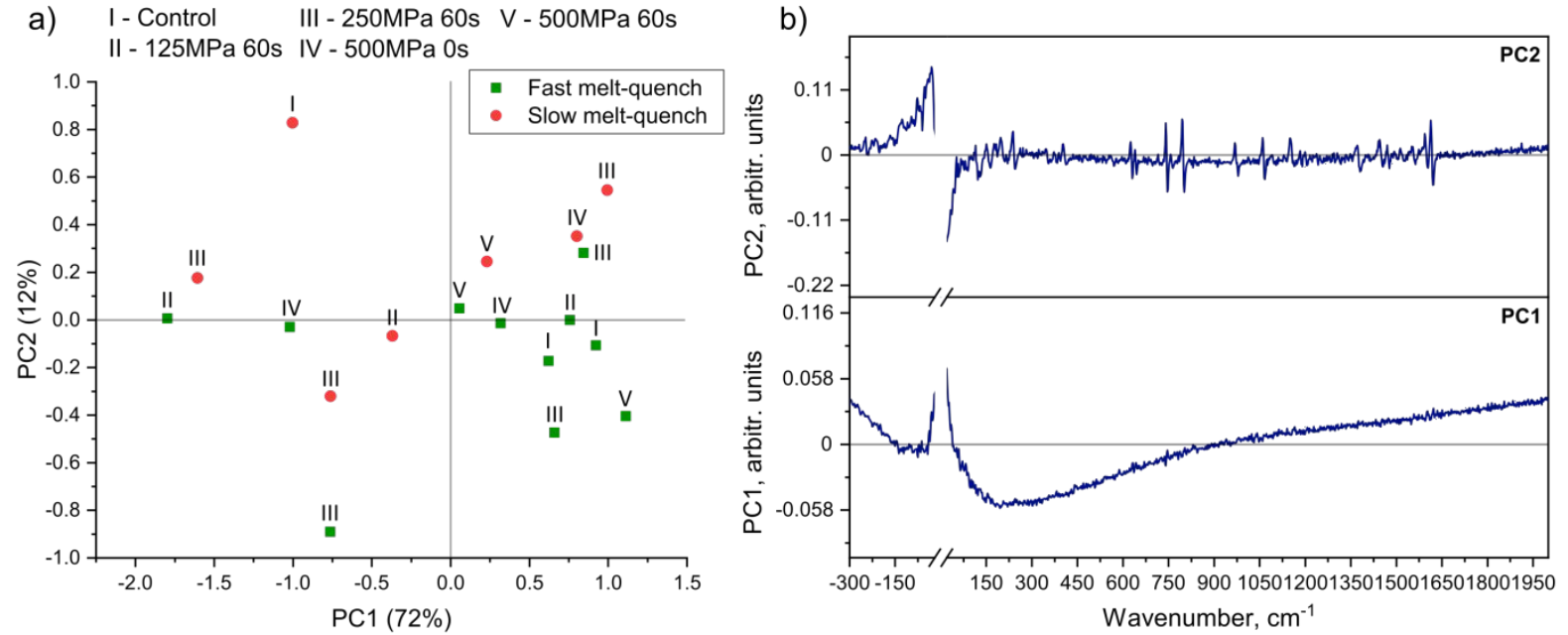

Figure S4. (a) Scores plot of PC1 versus PC2 and (b) the first two loadings plots from principal component analysis (PCA) of the initial spectra of the DOE samples (Table S1). 


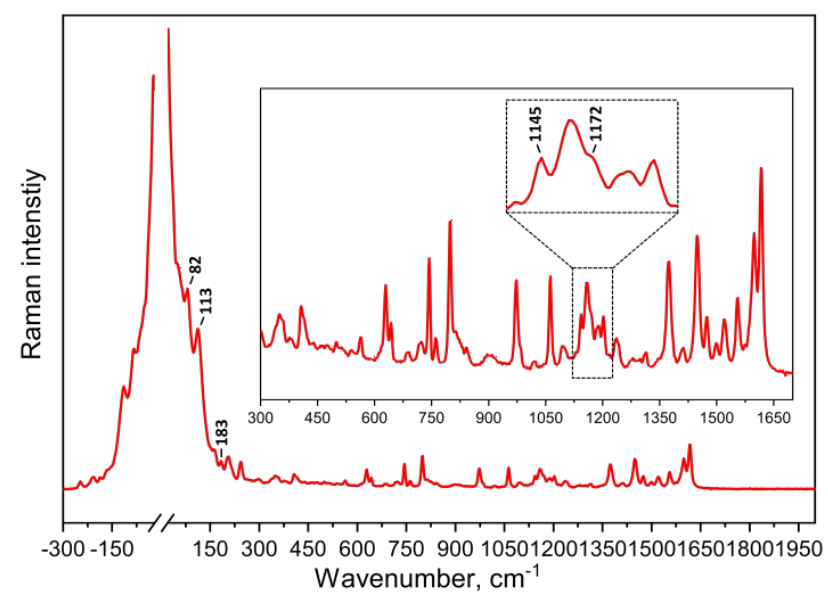

Figure S5. Example of a Raman spectrum for amorphous celecoxib heated at $80{ }^{\circ} \mathrm{C}$ for approximately one hour; full data and mid-frequency range (inset). The highlighted peaks denote presence of formed crystalline celecoxib (assumed to be form I and/or form II), while rest of the spectral features correspond to amorphous celecoxib.

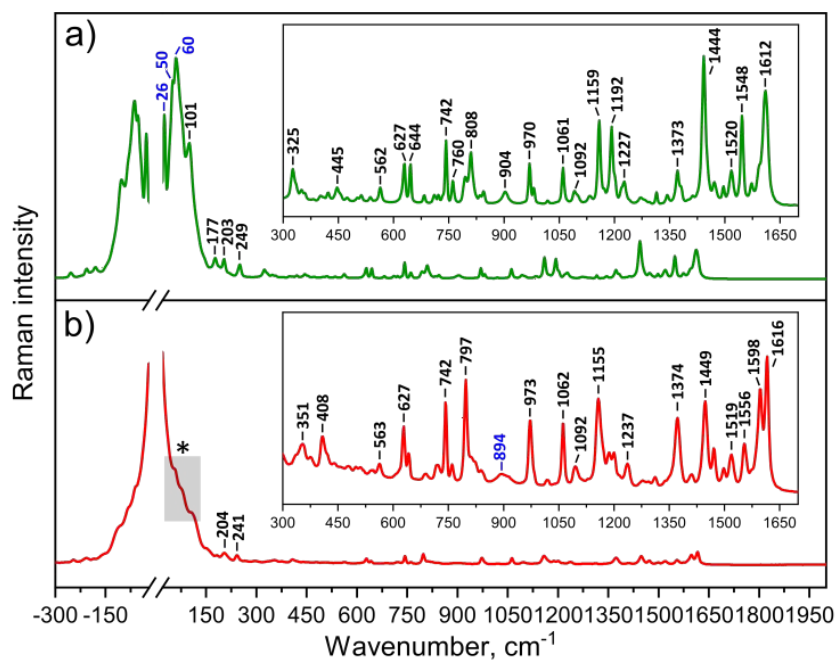

Figure S6. Resolved MCR loadings spectra of (a) component 2 (form III) and (b) component 1 (amorphous celecoxib); full data and mid-frequency range (insets). Blue labels denote peaks whose positions have been slightly affected by the temperature effect. Highlighted area (marked with *) in the LFR spectral range for the amorphous component is associated with resolved negligible contributions from the form I and/or form II formed during the temperature ramp phase (from 20 to $90{ }^{\circ} \mathrm{C}$ ) for some of the samples. 